\title{
Moçambique: Identidade, colonialismo e libertação: Não vamos esquecer!
}

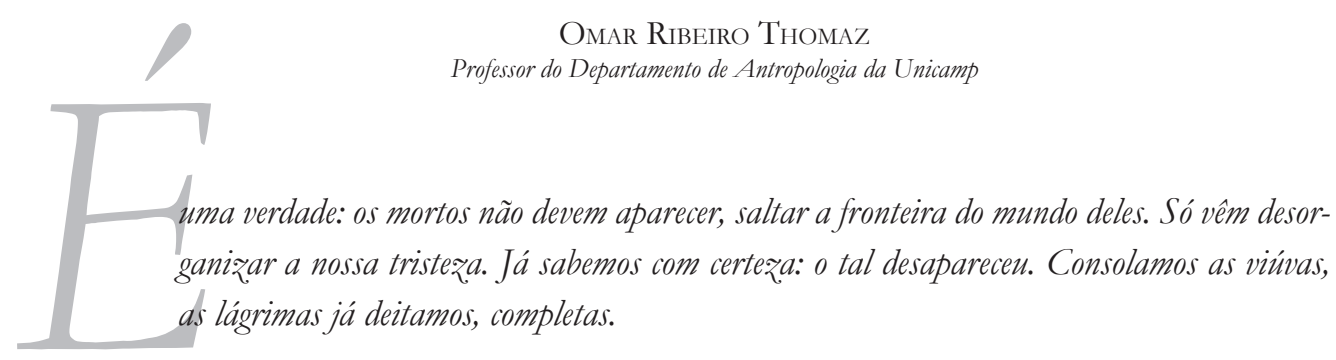

Ao contrário, há desses mortos que morreram e teimam em aparecer (...). Morreram por dentro da água, pescados pelo rio furioso. A morte deles era uma certeza quando uma tarde apareceram mais outra vez:

"A história dos aparecidos". In: Vozes Anoitecidas, Mia Couto

Em Moçambique, o passado é presente. As conversas cotidianas - e os moçambicanos de todos os grupos sociais curtem um bom papo - são entremeadas constantemente por referências temporais, algumas difusas, outras precisas, mas todas cruciais para a compreensão dos acontecimentos presentes. Quando nos aproximamos do "mato", são frequentes as narrativas sobre "aqueles tempos" - geralmente os tempos antigos, muitas vezes anteriores ao estabelecimento dos portugueses na região. No sul, são os tempos das invasões Nguni e da formação do Império de Gaza, tempos em que as linhagens se perdem e estão mais além de uma memória que dificilmente vai além da terceira geração, tempos do grande imperador, de guerras de conquista e de grandes feiticeiros. O ouvinte pouco habituado a estas referências pode imaginar que estamos diante da ritualização do relembrar os tempos passados. Mas é muito mais que isso. Os tempos das guerras antigas nos falam de conquistas que começaram "naqueles tempos", mas que alimentam desconfianças contemporâneas; nos falam de antepassados mortos que não 
foram devidamente enterrados e que portanto retornam, atormentando seus descendentes, exigindo o pagamento de velhas dívidas. Os antepassados são muito mais que memória: são personagens que estão ao nosso lado, comem, trabalham, amam e odeiam, ajudam-nos e vingam-se.

No "mato", mas também longe dele, no "caniço" ou no "cimento", são cotidianas as histórias sobre o "tempo colonial". Trata-se de um longo período, entrecortado por matizes de toda a ordem. Alguns se lembram que, na altura, os preços eram mais baixos, que com escudos moçambicanos ou libras sul-africanas podia-se comprar muito mais que com os atuais meticais moçambicanos. Mas todos recordam os trabalhos forçados. Invariavelmente quando inquiridos sobre lembranças antigas, os mais velhos recorrem à imagem de homens atados por correntes indo para a labuta ou trabalhando nas obras públicas, nos caminhos de ferro, nas estradas. Suas lembranças são conflitantes com aquelas reivindicadas por outros que também insistem em cultivar a memória, portugueses coloniais - neste caso, geralmente memórias marcadas fundamentalmente pela nostalgia. Estes afirmam o equilíbrio do período colonial, a hierarquia regulada pelo espírito português. É o lusotropicalismo. Geralmente, os moçambicanos do "mato", do "caniço" e do "cimento", do norte, do centro e do sul são enfáticos: o equilíbrio colonial se mantinha, entre outras coisas, pelo peso do aparato estatal colonial, e pelas múltiplas possibilidades dos colonos e descendentes em explorar o trabalho “indígena”. Quando um português, ou um branco, caminhava pelo meio-fio da antiga Lourenço Marques, atual Maputo, o negro moçambicano devia ceder a passagem; os empregados negros, geralmente homens, eram todos chamados de "rapaz", o correspondente lusitano para o boy dos ingleses. O quão doloroso era para um senhor africano ser chamado de "rapaz" por um jovem branco, em sociedades tão marcadas por clivagens de autoridade e respeito entre os grupos etários!

As lembranças coloniais - refiro-me aos antigos colonos - vão noutra direção. A sociedade branca colonial se defendia numa poderosa estrutura de autoajuda, e se houve colonos pobres, estes não só foram minoritários como tinham que desaparecer. O colonialismo contemporâneo na África, particularmente naquelas colônias com presença branca significativa tais como Angola e Moçambique, Quênia, Rodésia do Sul e África do Sul se constitui num aprofundamento da segregação racial que, entre outras coisas, defendia 
o colono diante do nativo, e impedia a pobreza branca. Atrelado ao sistema capitalista, sim, mas como uma extraordinária máquina de ação afirmativa voltada para a construção e manutenção de uma elite quase que exclusivamente branca.

Não são poucos os que recordam os castigos físicos, ou a sua possibilidade do castigo, pelo menos até meados dos anos 1950 e, em algumas regiões, até finais dos anos 1960. Diante de uma suposta insubordinação do empregado, a palmatória, oficializada até um período tardio, era a prática. Todos lembram ainda dos transportes públicos na Beira ou em Lourenço Marques serem claramente segregados, com setores para brancos, mistos e assimilados, e setores para os negros. Mistos e assimilados estavam constantemente expostos ao constrangimento de ter o seu status questionado; negros, estes deveriam ir numa parte específica do ônibus ou do bonde, e mesmo quando houvesse cadeiras vagas no setor dos "civilizados", deveriam ir em pé na parte reservada aos "indígenas". Cinemas também eram separados, assim como o clube e as associações, o baile, ou a praia - na praia do Polana, negros só como empregados.

O "tempo colônia" era o tempo das fronteiras e da sua ritualização cotidiana: brancos não deviam se misturar com os negros, e tampouco com os mulatos e os assimilados; mulatos, ou mistos, tampouco deviam se misturar com os negros; os indianos deviam viver entre si, assim como os chineses. A hierarquia do império assim o exigia: longe da retórica luso-tropical que passa a dominar o aparato colonial português progressivamente a partir de meados dos anos 1950, qualquer mescla era indesejável, qualquer relação afetiva vigorosa e socialmente coibida.

A construção de Moçambique na sua contemporaneidade passa pelas histórias dos tempos antigos, histórias sobre "os tempos"; e passa pelas histórias do colonialismo, o "tempo colônia". A identidade moçambicana contemporânea cruza identidades construídas em meio à institucionalização do Estado colonial, em meio a guerra de libertação e a formação do país como Estadonação independente.

Em Moçambique: identidade, colonialismo e libertação, ${ }^{1}$ José Luís Cabaço interpela seu contato com as fontes, com os clássicos das ciências sociais e com os volumes da historiografia portuguesa e moçambicana com suas próprias

1 CABAÇO, José Luís. Moçambique: Identidade, colonialismo e libertação. São Paulo: Editora UNESP, 2009. 
memórias. Como para qualquer moçambicano, rememorar não constitui um exercício de nostalgia: quando José Luís se lembra, e faz eco à canção e à exigência de Samora Não vamos esquecer!, ele nos fala dos conflitos presentes do se país. De um pré-colonial que se adivinha aqui e ali e se anuncia numa possível interpretação da guerra civil recente; de um colonial que se respira na divisão urbana da cidade capital, nas relações entre patrões e empregados nos dias atuais, nos comportamentos assumidos por brancos que chegam em Moçambique ou retornam a este país, por negros que ascenderam; de um pós-colonial que se prometeu e se promete nas histórias dos heróis.

O texto de José Luís Cabaço confronta sua memória com a memória de seus interlocutores, e sua memória com os clássicos que se debruçaram sobre o colonialismo que dominou o continente africano ao longo de boa parte do século XX. A etnografia aqui não constitui uma parte separada do texto. Seus interlocutores narram o que viveram e o que, sabem, foi vivido, da mesma forma que Cabaço não abre mão da sua memória e de se situar no contexto presente. Em seu texto, ele nos relata um entrelaçar de histórias, que também é a sua. E sem para isso se transformar numa espécie de eixo central da narrativa, tão ao gosto de uma certa antropologia pós-moderna que, por sorte, parece ter ficado para trás. A experiência colonial de Cabaço surge lado a lado com a daqueles que com ele conversaram ao longo de sua pesquisa, e com aquelas que estão um pouco por toda a parte, de norte a sul do país.

A forma como nos conta a história da bolachada que recebeu numa determinada ocasião de sua infância e sua importância é reveladora da atitude narrativa de Cabaço, que nos diz:

"Tinha 13 anos e frequentava a que então era a única escola oficial de Moçambique, o Liceu Salazar, na cidade capital. Morava longe e ia de bicicleta às aulas. Uma manhã, ainda distante do Liceu, vejo um colega - um dos três colegas negros - correndo, porque se havia atrasado. Ofereci-lhe uma boleia na bicicleta. Quando regressei das aulas, o familiar em casa de quem eu vivia recebeu-me com uma punição. Alguém lhe tinha telefonado informando que eu carregara na minha bicicleta um negro o que, não sendo ilegal, constituía uma violação dos códigos de autodefesa dos colonos. Era o poder disciplinar supervisionando". 
Mais adiante, José Luís Cabaço nos conta do empregado que trabalhava em sua casa quando ele tinha por volta de vinte anos, no início dos anos 1960, Rafael Arcanjo. José Luís lembra-se que compartilhavam a paixão pelo futebol, e torciam pelo mesmo clube, o Desportivo. Já passando por um processo que o levaria a afirmar-se como moçambicano, e aliar-se aos demais grupos que lutaram pela independência do seu país, José Luís procura romper a barreira, e convidar Rafael para, com ele, ir ao jogo do Desportivo no domingo. "Quando comprei os ingressos" - lembra-se José Luís cabaço -,

ele [Rafael, o empregado] não me quis acompanhar na bancada dos 'civilizados'. Ele sabia que, na minha companhia, poderia sentar-se naqueles lugares, mas preferiu a bancada dos 'indígenas', do outro lado do estádio. 'Então vamos os dois para lá, disse eu. Rafael olhou-me assustado e percebi que me implorava que o não fizesse. Fiquei muito perturbado, mas contrariá-lo seria uma posição arrogante e autoritária da minha parte e, provavelmente, o fim de uma possível amizade. No fim do jogo, voltamos a encontrar-nos para regressarmos a casa e só comentamos a partida.

A história com Rafael Arcanjo continua, numa das páginas mais impressionantes do trabalho de Cabaço: Rafael, revelando o gosto pela fofoca, faz com que José Luís perceba que

na relação doméstica, o 'criado' era 'invisível' aos olhos dos colonos; fazia parte da casa como as paredes e o mobiliário. As conversas dos 'patrões', e seus comportamentos decorriam sem quaisquer inibições perante aquele 'objecto' que, sendo parte do ambiente, deslizava silenciosamente entre os membros da família realizando as tarefas da casa. Através de seus colegas, Rafael sabia (e contava obviamente sobre a casa onde trabalhava) da vida de cada vizinho, dos hábitos de todos eles, de quem maltratava os empregados, dos 'patrões' que insultavam e até batiam nas mulheres. Até casos de infidelidade conjugal no bairro Rafael me relatava entre gostosas gargalhadas de ambos. O tema criou cumplicidade entre nós. Eu sentia-me entrando num novo mundo, que sempre estivera ali sob meus olhos e que eu nunca fora capaz de ver. 
Como não lembrar das vigorosas páginas de Doris Lessing que, em seu Canção da relva foi capaz de relatar o inconcebível, a relação entre um criado africano e uma patroa europeia! Como não lembrar dos inúmeros romances coloniais portugueses, onde os empregados "pretos" são destituídos de qualquer sorte de personalidade, caráter ou subjetividade, para subsumirem numa entidade genérica, “os pretos”! Como não pensarmos na situação contemporânea de Moçambique, onde brancos residentes neste país retomam o mesmo tipo de padrão diante de seus empregados, assim como a própria elite negra!

As páginas de Cabaço sobre o luso-tropicalismo ganham em sofisticação na medida em que ele nos revela a pouca importância que a obra luso-tropical de Freyre teve entre as elites africanas nacionalistas que se formavam. Numa conversa que tivera com Mário Pinto de Andrade, o intelectual angolano fora enfático: após o início da guerra, o luso-tropicalismo não era tema entre os promotores dos movimentos de libertação nacional. Merecia atenção enquanto aquilo que era: ideologia perpetuadora do poder colonial português. Não chegou a provocar as intelectualidades nascentes na Guiné-Bissau, em Angola ou em Cabo Verde. Na direção inversa ia a leitura dos romances realistas e regionalistas brasileiros - estes portadores de uma vivacidade que despertavam o leitor para os conflitos próprios da sociedade brasileira, para além de proporem um uso da linguagem inspirador para aqueles que, do lado africano, estavam às voltas com o esforço de quitar de Portugal e dos portugueses uma autoridade gramatical, moral ou histórica sobre a língua portuguesa. Se em Portugal o luso-tropicalismo de Freyre tarda em ser aceito - pois este país pretendia ser, nas primeiras décadas do século XX, nada mais, nada menos que uma metrópole colonial europeia como qualquer outra, ou seja, promotora de um regime de segregação racial tradutor de uma boa administração -, nas colônias em geral, em Moçambique em particular, o luso-tropicalismo era recebido, no mínimo, com estupor. Como reivindicar tolerância numa sociedade que se reproduzia em meio à palmatória e aos trabalhos forçados? Como falar de luso-tropicalismo onde o tropicalismo não fazia mais do que inventar um estilo de vida colonial (presente do outro lado da fronteira, nas colônias e protetorados britânicos), e o luso se expressava da mesma forma que o britânico, o belga ou o francês, por meio da segregação racial?

Quando chega aos anos da guerra de libertação, Cabaço confronta as leituras africana e portuguesa da guerra, bem como um conjunto de lugares co- 
muns sobre as guerras de insurgência construído ao longo da guerra fria, com os relatórios coloniais portugueses, com sua própria memória e com os relatos daqueles que fizeram a guerra. E aqui dá um passo crucial na análise do período: assumir que ao lado da gênese do nacionalismo moçambicano, base da guerra de libertação, temos a gênese de outro pensamento e prática, aquele responsável por um africanização da guerra. Jorge Jardim é aqui exemplar não apenas como o formulador da possibilidade de uma independência branca para Moçambique, mas enquanto um dos agentes promotores pela formação de novos grupos em solo africano, algo crucial para a compreensão dos conflitos ulteriores, da guerra civil que assola o país a partir de finais dos anos 1970.

Mas o relato de Cabaço termina com a independência do país, e com sua interpretação da opção socialista da FRELIMO. São poucas as vezes que temos a oportunidade de ler o resultado de um trabalho acadêmico que constitui concomitantemente o resultado de um esforço de ação, pois Cabaço desempenhou um papel decisivo na história de seu país, pré e pós independência. Seu livro é um convite para uma longa conversa, tão a gosto de José Luís Cabaço. A leitura de Moçambique: identidade, colonialismo e libertação é uma longa e deliciosa conversa. E neste papo intervêm os pensadores responsáveis pelo debate colonial e anticolonial; os homens de ação e de pensamento do colonialismo e do anticolonialismo. E o melhor da literatura sociológica e antropológica. Todos dialogando com as lembranças vivas dos próprios moçambicanos que, como Cabaço, e seguindo a sugestão de Samora Machel, se negam a possibilidade do esquecimento. 